\title{
Nutrients, oxygen, and inferred new production in the Northeast Water Polynya, 1992
}

\author{
D.W.R. Wallace and P.J. Minnett \\ Oceanographic and Atmospheric Sciences Division, Department of Applied Science, Brookhaven National \\ Laboratory, Upton, New York
}

\section{T.S. Hopkins}

Department of Marine, Earth and Atmospheric Sciences, North Carolina State University, Raleigh

\begin{abstract}
Nutrient and oxygen distributions were measured during a hydrographic survey of the Northeast Water Polynya off the northeast coast of Greenland $\left(77-81^{\circ} \mathrm{N}, 6-17^{\circ} \mathrm{W}\right)$ during July-August 1992 and were interpreted in the context of satellite imagery of the region. Satellite imagery revealed a convoluted plume of cold water flowing along isobaths from underneath fast ice in the southwestern portion of the polynya toward the northeast. This plume carried relatively high nutrient and low oxygen inventories. Nitrate to phosphate ratios were low in the polar water, consistent with an ultimate source of this water mass in the Pacific sector of the Arctic Ocean. It is hypothesized that the low N:P Arctic outflow might be the cause of nitrate limitation along the east coast of America as far as Cape Hatteras. Gradients of both nutrients and oxygen inventories in the euphotic zone were observed along and across the axis of mean flow within the polynya and are shown to be due to net production of organic matter. On the basis of these spatial gradients of nitrate and oxygen, an assumed along-axis current velocity of $10 \mathrm{~cm} \mathrm{~s}^{-1}$, and the observed relationships of biologically removed inorganic carbon with nitrate and oxygen, the net organic matter production was estimated to be $40-60 \mathrm{mmol}(\mathrm{C})$ $\mathrm{m}^{-2} \mathrm{~d}^{-1}$. This represents the organic carbon available for export from the polynya euphotic zone. Nutrient-deficient and oxygen-rich waters were observed merging with the southward flowing East Greenland Current, suggestive of possible export, however, the ultimate fate of organic carbon produced within the polynya requires further study.
\end{abstract}

\section{Introduction}

Polynyas (i.e., open water regions surrounded by ice) have been referred to as the "oases" of the Arctic [Struzik, 1989]. The absence of ice cover during the polar day, combined with a supply of nutrients advected from beneath the adjacent ice cover, provide the potential for high, localized biological productivity. This high productivity can provide a food source for higher trophic levels, including birds and marine mammals. For these reasons, polynyas are ecologically (and, in the Arctic, sociologically) important.

Polynyas also can serve as natural "laboratories" for the study of high-latitude biogeochemical and ecosystem processes. The ice edge provides a well-defined boundary separating regions of light-limited production beneath the ice from illuminated waters within the polynya. When combined with an advective supply of nutrients into polynya surface waters and appropriate advection timescales, an ecological progression from light limitation of phytoplankton growth, through rapid growth in the presence of abundant

Copyright 1995 by the American Geophysical Union.

Paper number $94 \mathrm{JC} 02203$.

0148-0227/95/94JC-02203\$05.00 nutrients, to nutrient-limited growth, may become established within a polynya. Whereas in most oceanic regions, such a progression is strictly temporal (e.g., seasonal), within a polynya a similar succession might be expressed spatially (e.g., along the axis of water flow into the polynya).

During July-August of 1992 a multidisciplinary research project [NEWATER Steering Committee, 1993] was conducted aboard the United States Coast Guard Cutter (USCGC) Polar Sea within the Northeast Water Polynya, a recurring, seasonal polynya located off the northeast coast of Greenland $\left(77-81^{\circ} \mathrm{N}, 6-17^{\circ} \mathrm{W}\right.$; see Figure 1). At that time the polynya was $\sim 10,000 \mathrm{~km}^{2}$ in extent. In this paper we discuss the distribution of dissolved nutrients and oxygen measured during this project, in the context of satellite images of the region, and distributions of heat and salinity. The data provide information on nutrient cycling and the magnitude of "new" or "export" production occurring within the polynya. This study is complementary to an analysis of inorganic carbon data collected at selected stations during the same research cruise [Yager et al., this issue] and the direct measurement of biological productivity [Smith, this issue]. Hydrographic and chemical data from the cruise are available in a data report [Wallace et al., 1995]. 


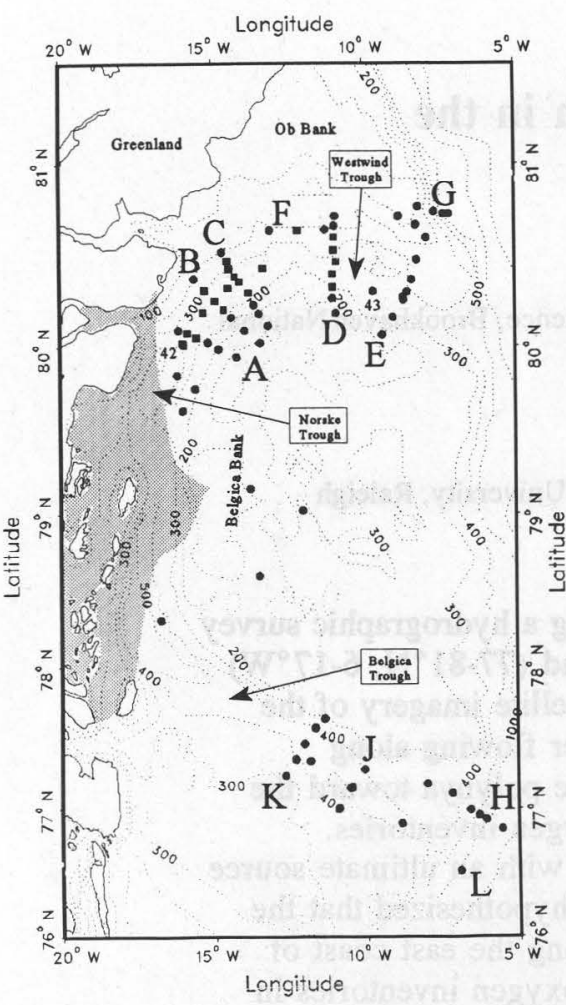

Figure 1. Map of the study region showing station positions, with the individual transects denoted by letters. The landfast ice is represented by the stippled area. In the text the Westwind and Norske Troughs north of $79.5^{\circ} \mathrm{N}$ are referred to as the Northern Trough; the Belgica Trough region is referred to as the Southern Trough.

\section{Methods and Techniques}

\subsection{Dissolved Oxygen}

Subsamples for Winkler titrations were drawn into $\sim 125$ $\mathrm{mL}$ flasks immediately after the rosette was brought on deck and samples had been withdrawn for chlorofluorocarbon analyses. These samples were analyzed following the methodology described by Carpenter [1965]. Subtle changes to methodology and calibration, as described by Culberson [1991], were implemented, so that the oxygen data meet the precision and accuracy guidelines of the World Ocean Circulation Experiment [WOCE, 1991]. Oxygen saturation was calculated using the solubility data of Benson and Krause [1984]. The bottle data were used to calibrate the response of a Beckman oxygen sensor attached to the conductivity-temperature-depth (CTD) package. Details of the oxygen sensor calibration, which employed the method of Owens and Millard [1985], are given by Wallace et al. [1995].

\subsection{Dissolved Nutrients}

Subsamples of $\sim 60 \mathrm{~mL}$ were drawn from the Niskin bottles within 10-20 min of the cast being complete. Phosphate, silicate, nitrate, nitrite, and ammonium were measured as soon as possible after sample collection (usually within 2-3 hours) using a Technicon Autoanalyzer II, following standard methods. The methods have been described by Whitledge et al. [1981], with the exception of the phosphate determination which used the hydrazinereductant method described by Gordon et al. [1991]. Standards were prepared in distilled, deionized water and low-nutrient surface seawater to determine the salt effect on colorimeter response and were run with each batch of samples. The wash water was distilled, deionized water.

\section{Descriptive Hydrography and Satellite Imagery}

\subsection{Topography/Ice Cover/Hydrography}

The topography of the region is presented in Figure 1, and the regional ice cover as seen in satellite imagery is shown in Figure 2. During July and August 1992 the polynya was located to the north and west of the Belgica Bank, extending to the Greenland coast in the west, and was bounded to the southwest by landfast ice (see Figure 1). Thus this tongue of landfast ice extended to the shallowest part of the Bank, where it was presumably grounded, and formed a canopy over the southwestern part of the trough system separating the Belgica Bank from Greenland. To the north the polynya was bounded by ice over the $\mathrm{Ob}$ Bank and to the east by ice in or from the East Greenland Current. To the southeast the edge of the polynya was determined by the high levels of ice cover over the Belgica Bank. Ice conditions during the summer of 1992 differed from the conditions reported by Bourke et al. [1987], who found much of the shallow water over the shelf to be ice free.

The troughs surrounding the Belgica Bank are relatively deep, exceeding $400 \mathrm{~m}$ in the north and $500 \mathrm{~m}$ in the south. They are the Westwind and Belgica Troughs, but for ease of description we will refer to them as the Northern and Southern Troughs. Hydrographic data suggest they are connected to the west through the Norske Trough but divided by a sill, with an effective depth of $250 \mathrm{~m}$, which presumably lies under the fast ice. Hydrographic measurements from Bourke et al. [1987], current measurements from this cruise (M. Johnson, unpublished data, 1994), and ice flow drift determined by inspection of satellite images, all imply a surface anticyclonic flow over the troughs around the Belgica Bank. This causes a northward surface flow in the southern part of the polynya, turning toward the east downstream. Mean flow velocity along the northern trough was $\sim 10 \mathrm{~cm} \mathrm{~s}^{-1}$.

The water mass structure on the shelf has been previously described by Bourke et al. [1987]. Polar water (PW) is defined as potential temperature $(\theta)<0^{\circ} \mathrm{C}$ and salinity (S) $<34.5$. The PW generally extends to depths of $\sim 150 \mathrm{~m}$ on the shelf and is underlain by Arctic Intermediate Water (AIW), defined as $0^{\circ} \mathrm{C}<\theta<3^{\circ} \mathrm{C}$ and $34.5<\mathrm{S}<34.9$. The PW within the polynya had been seasonally warmed to temperatures as high as $3^{\circ} \mathrm{C}$ and had been diluted with runoff and/or sea ice meltwater to salinities as low as 25 . Both the PW and the AIW are supplied to the region via the East Greenland Current (EGC), which is located close to the shelf break.

The $\theta-S$ diagram (Figure $3 \mathrm{a}$ ) indicates that the $\mathrm{PW}$ in the Southern Trough was significantly colder than that found in the Northern Trough. Note that a cold, high-salinity variant of PW (type B, the "knee" water of Bourke et al. [1987]) is 


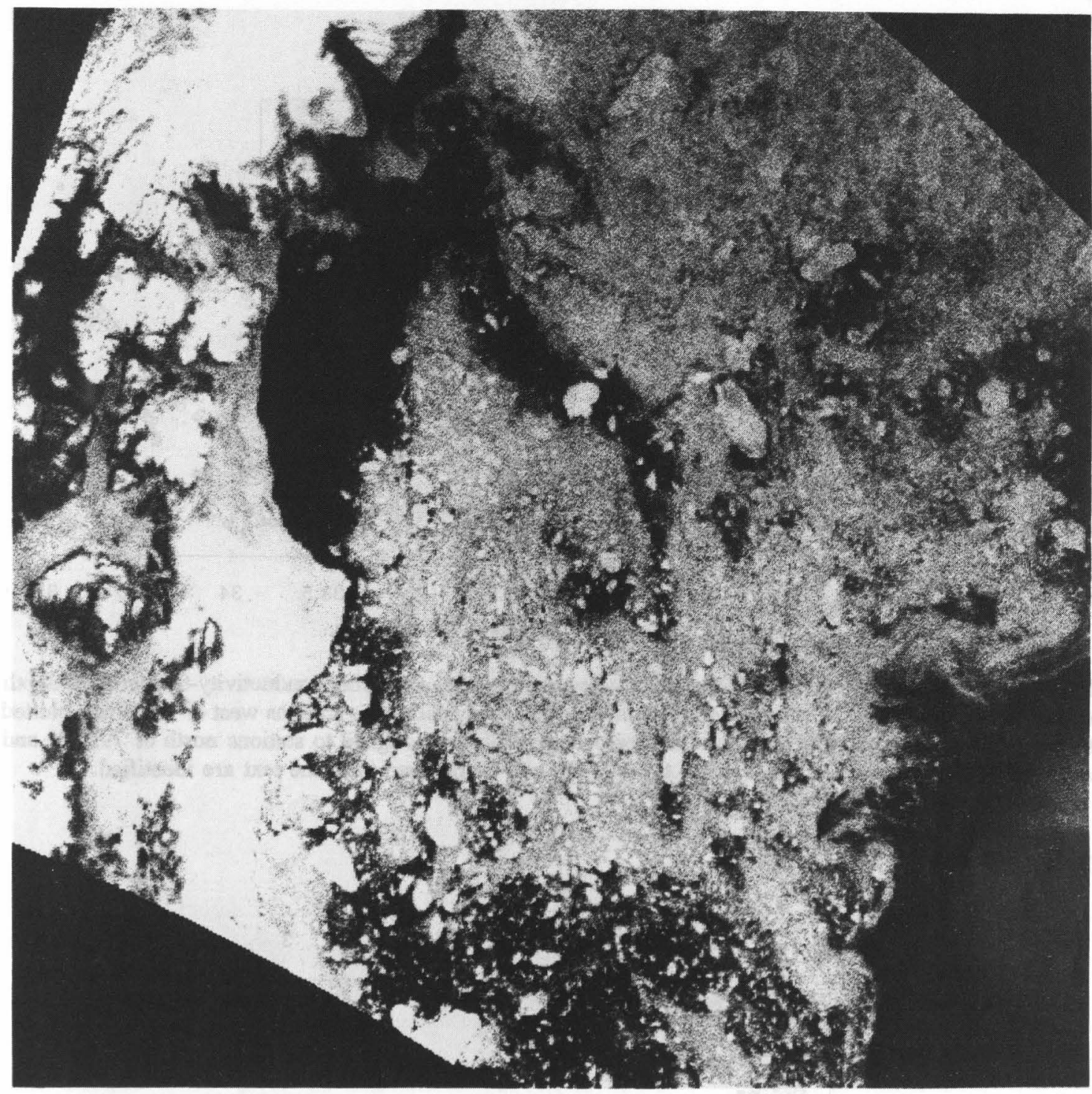

Figure 2. The extent and thermal structure of the Northeast Water Polynya is revealed in images taken by the advanced very high resolution radiometer (AVHRR) on the NOAA 11 polar-orbiting satellite on July 23, 1993, at 1209 UTC. The monochrome image from channel $1(\lambda \sim 0.65 \mu \mathrm{m})$ shows ice-free ocean as dark areas and ice cover as light tones. The image ia centered at $78.30^{\circ} \mathrm{N}, 10^{\circ} \mathrm{W}$, and the spatial extent of is about $512 \times 512 \mathrm{~km}$, with a resolution of $\sim 1 \mathrm{~km}^{2}$.

not found in the Northern Trough. Bourke et al. [1987] attributed this water type to a deep, eastern origin within the EGC. The vertical $\theta$ and $S$ profiles (Figures $3 b$ and $3 c$ ) from the northern region suggest that the $\mathrm{PW}$ over the shelf convects to depths of $\sim 125 \mathrm{~m}$ in winter and that the resulting water type is at the freezing point and has a salinity of $\sim 32.4$ (type A on Figure 3a). Hence while this remains a variant of $\mathrm{PW}$, it has been locally modified on the shelf. The $\theta-S$ diagram (Figure 3a) for the Northern Trough suggests that water beneath this locally formed water type forms a mixing triangle. The three components appear to be the type A and type B waters which, in turn, mix with the underlying AIW (type C). It appears that this mixing occurs progressively during circulation around and over Belgica Bank.
Thermal infrared images from the advanced very high resolution radiometer (AVHRR) (Plate 1) show a plume of cold surface water emerging from underneath the fast ice and extending along the axis of the polynya, roughly parallel to the isobaths. The surface plume leaves the ice edge at a temperature close to the freezing point, and the thermal contrast is provided on both sides of the plume by surface waters that have been resident in the polynya sufficiently long to be heated by the insolation [Minnett, this issue].

\subsection{Northern Trough Sections}

Temperature, salinity, nutrient, and dissolved oxygen saturation sections from two cross-trough transects (A and D) in the Northern Trough (see Figure 1) are shown in Figures 4 and 5. Ammonium levels were measured on all 


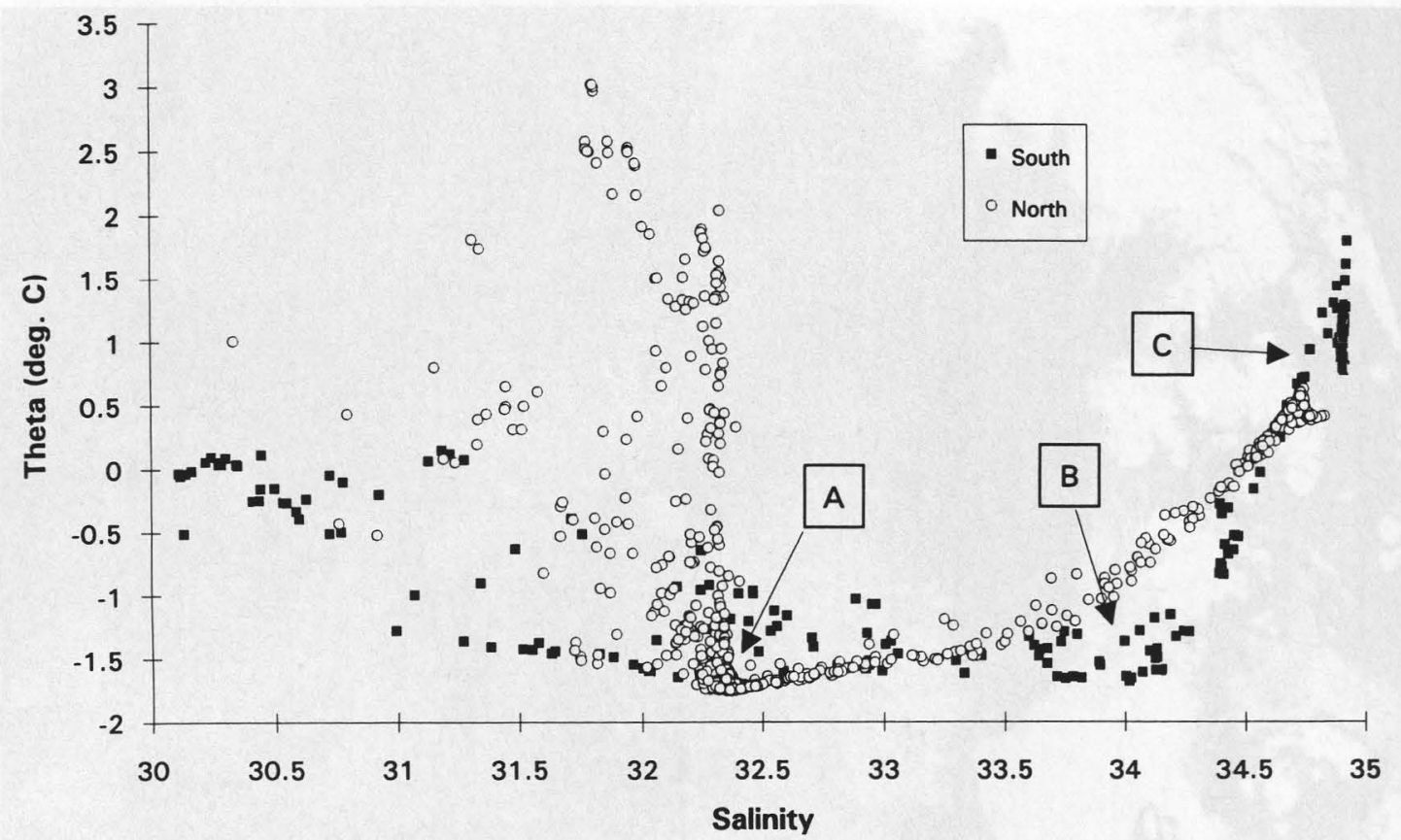

Figure 3a. Potential temperature ( $\theta$ or theta) versus salinity diagram using conductivity-temperature-depth (CTD) data recorded at the time of sample bottle closing. Only data from stations west of $10^{\circ} \mathrm{W}$ are plotted to avoid East Greenland Current stations. Separate symbols are assigned to stations north of $79.5^{\circ} \mathrm{N}$ and south of $78.5^{\circ} \mathrm{N}$. Three principal water types (A,B, and C) referred to in the text are identified.

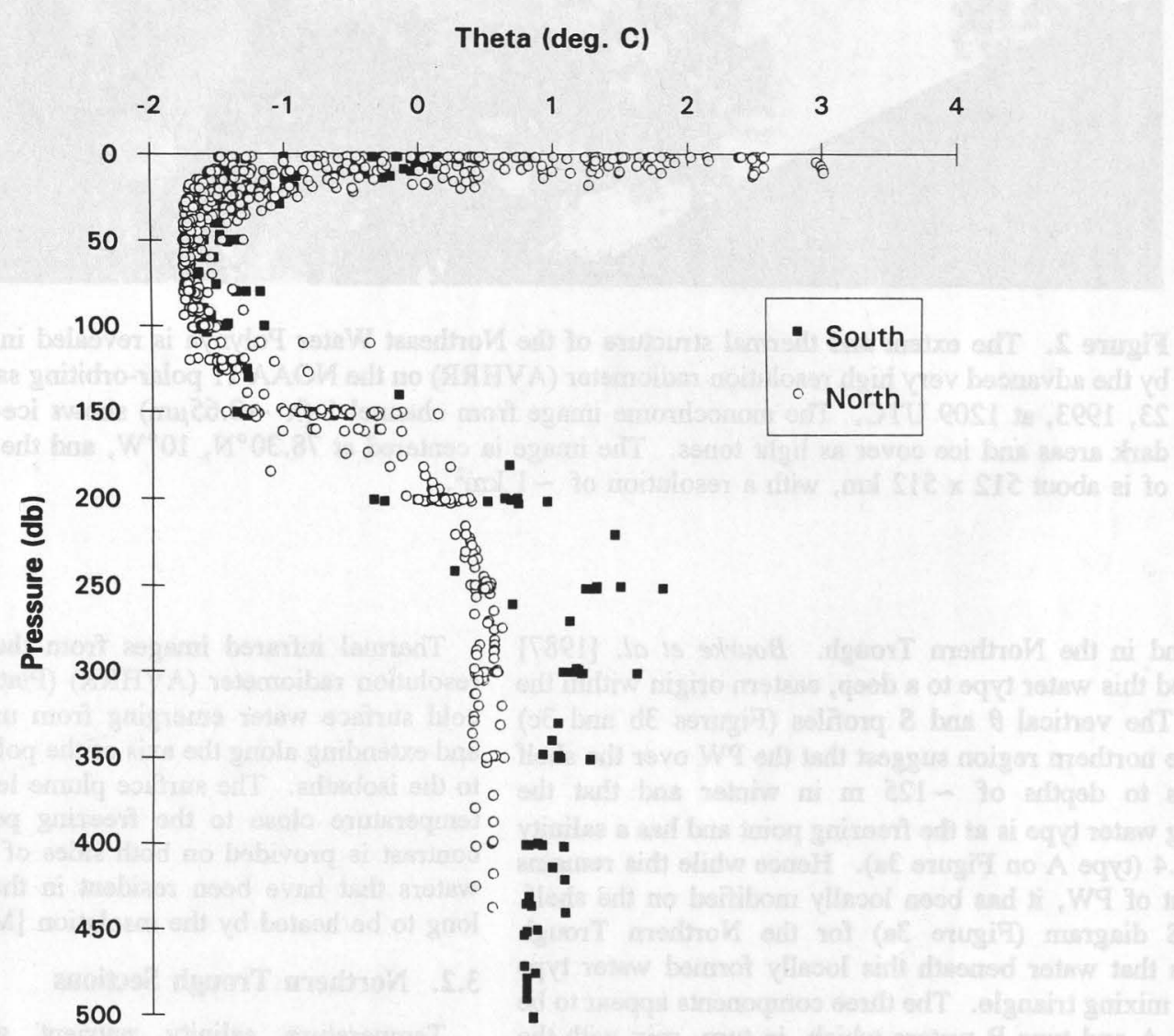

Figure 3b. Potential temperature depth profiles with separate symbols for northern and southern stations as in Figure 3a. 


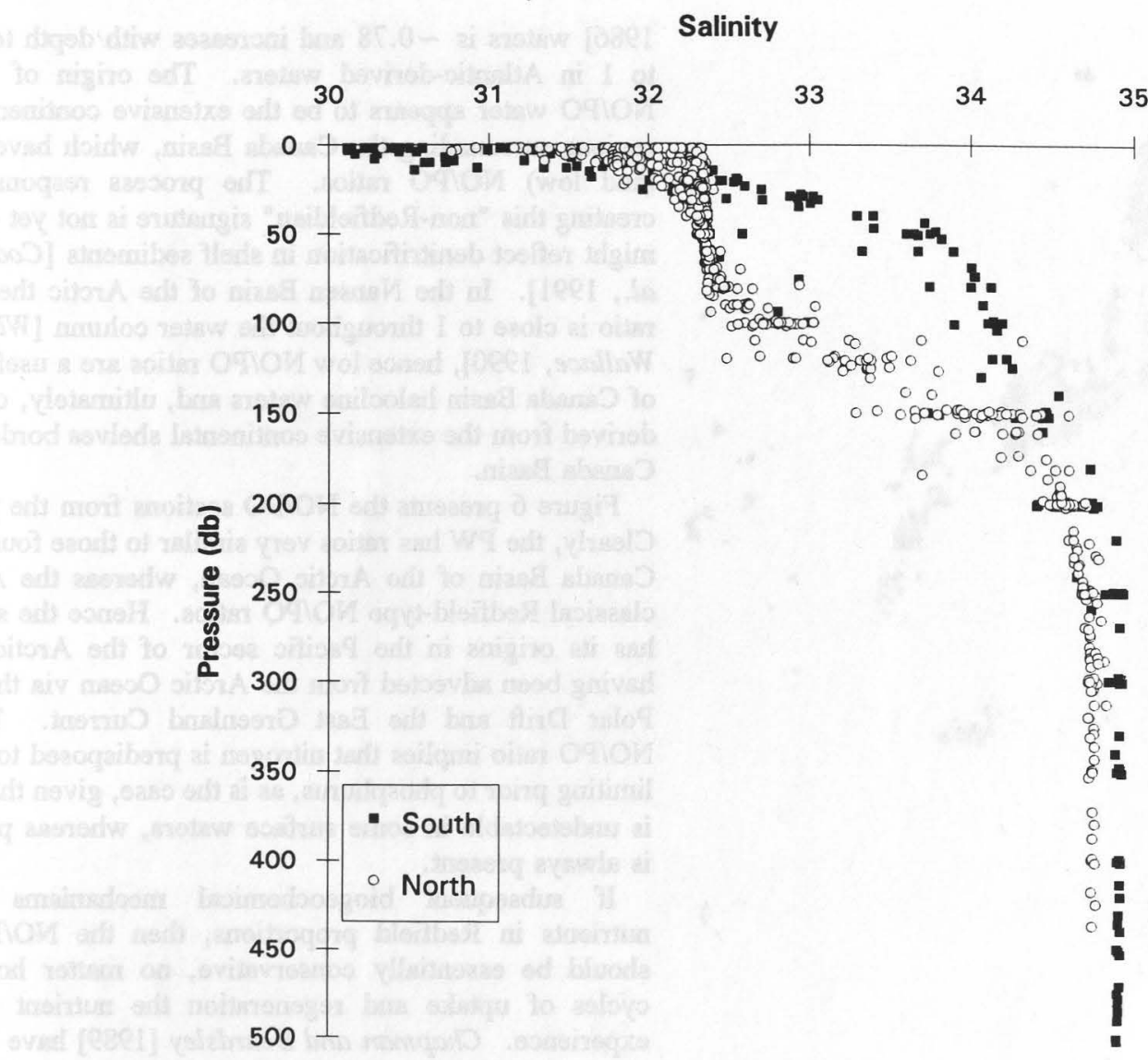

Figure 3c.Salinity depth profiles with separate symbols for northern and southern stations as in Figure 3a.

water samples but were almost always low $(0.09 \pm 0.12$ $\mu \mathrm{mol} \mathrm{kg}^{-1}$ for depths $<70 \mathrm{~m}$ ); when higher levels were occasionally encountered, they appeared to be correlated with higher zooplankton abundance (C. Ashjian and K. Daly, personal communication, 1994).

Nitrate levels in the AIW are $\sim 13.5 \mu \mathrm{mol} \mathrm{kg}{ }^{-1}$ and show little or no variation between sections. Obvious in each section is a layer of relatively uniform nitrate $(5-7 \mu \mathrm{mol}$

$\mathrm{kg}^{-1}$ ) between depths of $50-100 \mathrm{~m}$, underlain by a strong nitrate gradient corresponding with the halocline. Within the $\mathrm{PW}$, surface levels at transect $\mathrm{A}$ range from $\sim 2$ to $>4$ $\mu \mathrm{mol} \mathrm{kg} \mathrm{kg}^{-1}$, whereas at transect D all surface levels are $<2$ $\mu \mathrm{mol} \mathrm{kg}^{-1}$. Surface nitrate levels were often below our

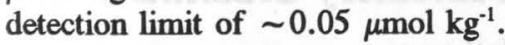

Phosphate levels, by contrast, show relatively little vertical variation, although a slight maximum was evident between 50 and $100 \mathrm{~m}$ in most sections, associated with a salinity of $\sim 32.4$. Surface phosphate was always readily detectable, with the minimum measured concentration being $\sim 0.6 \mu \mathrm{mol} \mathrm{kg}^{-1}$.

Silicate showed depletion to near-zero levels in the upper $10 \mathrm{~m}$ at some stations. A clear silicate maximum (occasionally $>12 \mu \mathrm{mol} \mathrm{kg}$ ) was evident in all transects at $100-120 \mathrm{~m}$ depth, becoming stronger toward the east, and was associated with a salinity of $\sim 32.5$. This is similar to observations from the EGC reported by Anderson and Dyrssen [1981], who suggested the high-silicate core is a remnant of the central Arctic silicate maximum which is found at slightly higher salinities [Moore et al., 1983; Jones and Anderson, 1986].
Dissolved oxygen saturation was highest in very nearsurface layers, exceeding $120 \%$ at many stations, and as high as $137 \%$ at $3-5 \mathrm{~m}$ depth at station 7 . The mean saturation for the upper $5 \mathrm{~m}$ was $115( \pm 7) \%$. Some of this supersaturation is undoubtedly due to seasonal warming of the upper layers with surface layer temperatures as much as $4.2^{\circ} \mathrm{C}$ higher than their presumed initial temperature (the freezing point). Assuming no gas exchange, such warming would produce $\sim 111 \%$ saturation. Hence a significant proportion of the observed surface supersaturation of oxygen must also be due to net photosynthesis. The PW at 50-100 $\mathrm{m}$ has relatively constant oxygen saturation, in the range $95-100 \%$. This likely reflects the oxygen saturation at the time of winter convection, and similar slight undersaturation in wintertime ice-covered shelf waters of the Bering Sea has been reported [Chen, 1985]. The deeper AIW in the Northern Trough has a relatively constant oxygen saturation of $\sim 83 \%$.

\subsection{NO/PO Sections}

The discussion above indicates significant differences in the vertical distributions of the three nutrients. This is due to the different origins of the layered water masses found in the polynya region as follows: an Arctic Ocean source for the PW, and the Atlantic Ocean as a source for the AIW.

Wilson and Wallace [1990] showed that based on nutrient data, it is possible to define two separate water mass families in the Arctic Ocean. Quasi-conservative derived parameters were used based on the "Redfield" stoichiometric ratios [Redfield et al., 1963] of "NO" $\left(9 \times \mathrm{NO}_{3}+\mathrm{O}_{2}\right.$; see 


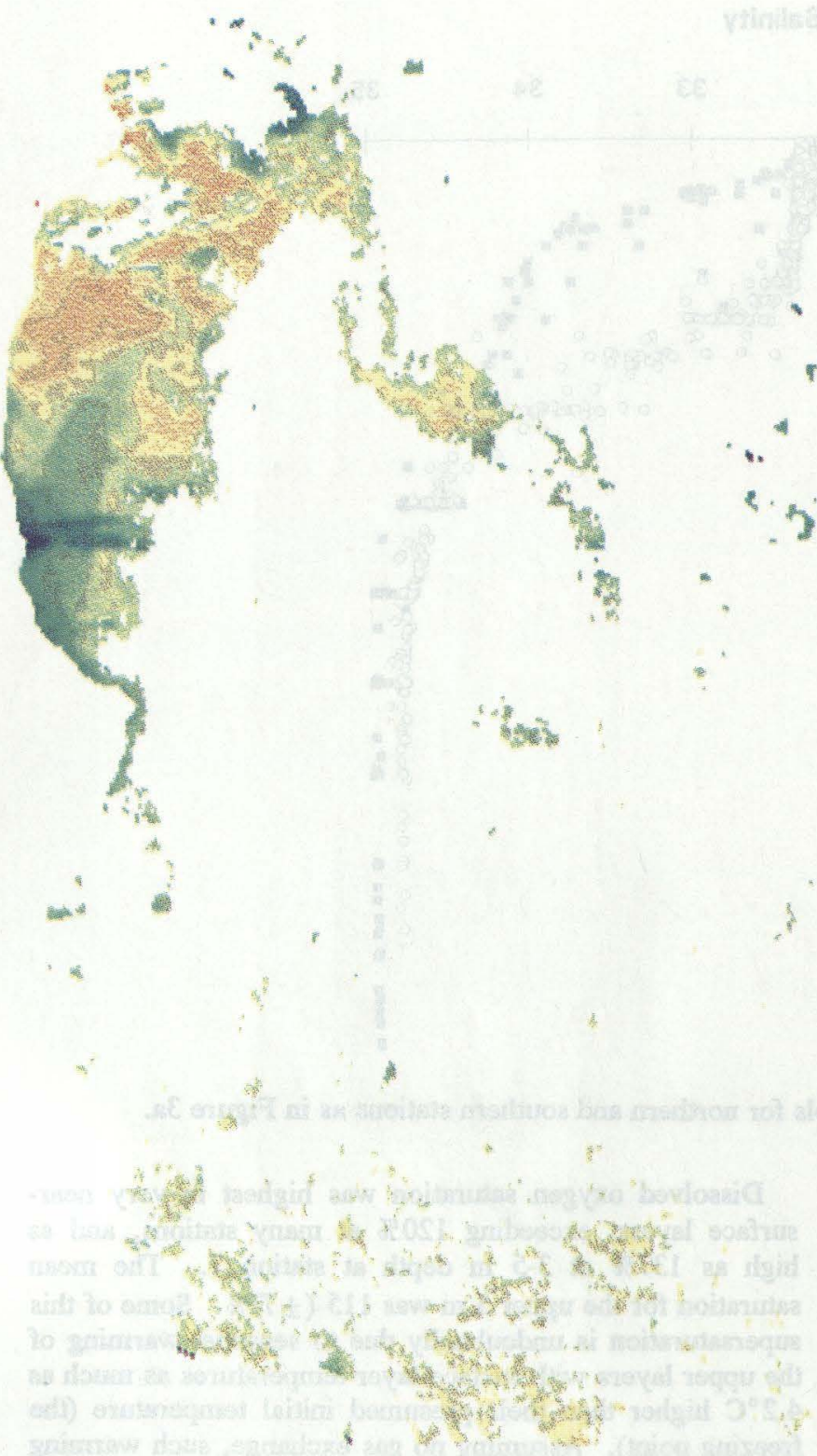

Plate 1. The false-colored image is from channel $4(\lambda$ $\sim 11 \mu \mathrm{m}$ ) and shows temperature variations in the open water, the ice cover having been masked out. (The two dark green, cold bands crossing the southern part of the polynya are the result of two thin cloud streaks.) The location and size of the image is the same as in Figure 2. Note the plume of cold water emerging from underneath the landfast ice in the southwestern polynya and moving to the northeast. Farther into the polynya, the plume appears to be squeezed between two areas of warmer water to the north and south, resulting in a thin, meandering stream.

Broecker [1974]), the analogous "PO" $\left(135 \times \mathrm{PO}_{4}+\mathrm{O}_{2}\right)$, and the ratio NO/PO. For a water mass which has nitrate and phosphate in the normal oceanic "Redfield" proportions the NO/PO ratio will be $\sim 1$; deviations from this ratio reflect the integrated effects of biogeochemical processes which do not correspond to the normal stoichiometry of marine organic matter.

In the central Canada Basin of the Arctic Ocean the NO/PO of surface and upper halocline [Jones and Anderson,
1986] waters is $\sim 0.78$ and increases with depth to $\sim 0.98$ to 1 in Atlantic-derived waters. The origin of this low NO/PO water appears to be the extensive continental shelf regions surrounding the Canada Basin, which have distinct (and low) NO/PO ratios. The process responsible for creating this "non-Redfieldian" signature is not yet clear but might reflect denitrification in shelf sediments [Codispoti et al., 1991]. In the Nansen Basin of the Arctic the NO/PO ratio is close to 1 throughout the water column [Wilson and Wallace, 1990], hence low NO/PO ratios are a useful tracer of Canada Basin halocline waters and, ultimately, of waters derived from the extensive continental shelves bordering the Canada Basin.

Figure 6 presents the NO/PO sections from the polynya. Clearly, the PW has ratios very similar to those found in the Canada Basin of the Arctic Ocean, whereas the AIW has classical Redfield-type NO/PO ratios. Hence the shelf PW has its origins in the Pacific sector of the Arctic Ocean, having been advected from the Arctic Ocean via the TransPolar Drift and the East Greenland Current. The low NO/PO ratio implies that nitrogen is predisposed to become limiting prior to phosphorus, as is the case, given that nitrate is undetectable in some surface waters, whereas phosphate is always present.

If subsequent biogeochemical mechanisms process nutrients in Redfield proportions, then the NO/PO ratio should be essentially conservative, no matter how many cycles of uptake and regeneration the nutrient elements experience. Chapman and Beardsley [1989] have hypothesized, on the basis of oxygen isotope data, that shelf water of the Middle Atlantic Bight off the eastern coast of the United States, belongs to a $5000-\mathrm{km}$ long, buoyancy-driven coastal current originating along the southern coast of Greenland. Although the limited oxygen isotope data available indicate that there must be a significant freshwater source between the NEW polynya region and the southern Greenland shelf, it remains likely that the coastal current itself extends along the entire Greenland shelf as does the adjacent East Greenland Current. We therefore speculate that the nitrate limitation characteristic of U.S. east coast shelf waters in general [Ketchum et al., 1958; Ryther and Dunstan, 1971] may be caused by the low N:P ratios originating in the Arctic Ocean.

\section{Inventories and Inventory Gradients}

\subsection{Inventory Calculations}

In order to assess the biological uptake of nutrients, we calculated inventories of nitrate, phosphate, silicate, and oxygen from the surface to $70 \mathrm{~m}$. This depth was chosen as it represents the core of the PW and also approximates the deepest $1 \%$ light level (i.e., euphotic zone depth) encountered during the cruise [W. Smith, unpublished data, 1994]. It is therefore unlikely that significant net production of organic matter occurred deeper than $70 \mathrm{~m}$ at any stage during the development of the polynya, making this an appropriate reference point for the integration of biogeochemical parameters, as well as heat. The temperature and salinity suggest this water has remained unchanged since the time of winter convection (see Figure 3). Some near-surface water had been warmed, and, also, its salinity had been reduced as a result of sea ice meltwater and/or runoff 

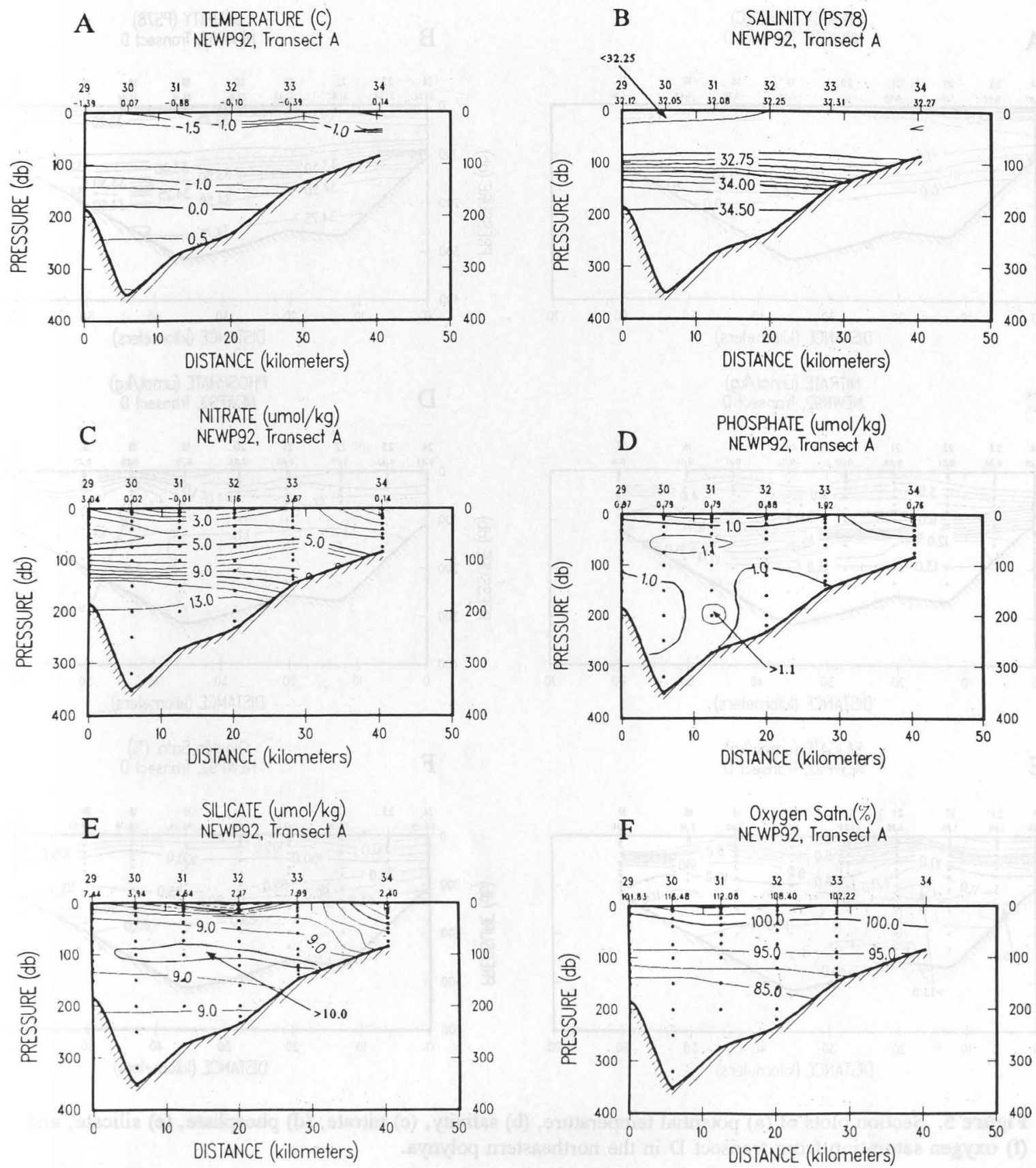

Figure 4. Section plots of (a) potential temperature, (b) salinity, (c) nitrate, (d) phosphate, (e) silicate, and (f) oxygen saturation from transect $\mathrm{A}$ in the southwestern polynya.

additions. Both freshwater sources will act to dilute the nutrient content of seawater, however, it is not possible to say whether the dilution would have occurred before or after any nutrients were removed by phytoplankton. For this reason, we also calculated inventories based on normalized nutrient concentrations, where the concentrations were normalized to a salinity of 32.4 which is the average salinity at $70 \mathrm{~m}$ (the PW core layer). The biological nutrient uptake, as deduced from inventory variations, should lie somewhere between estimates based on the normalized and nonnormalized inventories, however, we found little difference between these, and only the nonnormalized inventories are used subsequently. Inventories based on bottle data were only calculated for stations for which there were at least five measurements well spaced through the upper $70 \mathrm{~m}$.

Heat anomalies were also inventoried based on CTD data. At every depth a heat anomaly was calculated based on the temperature difference between the observed potential temperature and the freezing point for the salinity measured at that depth and the (salinity dependent) specific heat capacity.

\subsection{Heat, Nitrate, and Oxygen Inventory Distributions}

Plates $2 a, 2 b$, and $2 c$ show heat anomaly, nitrate, and oxygen inventories superimposed on a satellite thermal image of the polynya. This presentation allows the proper- 

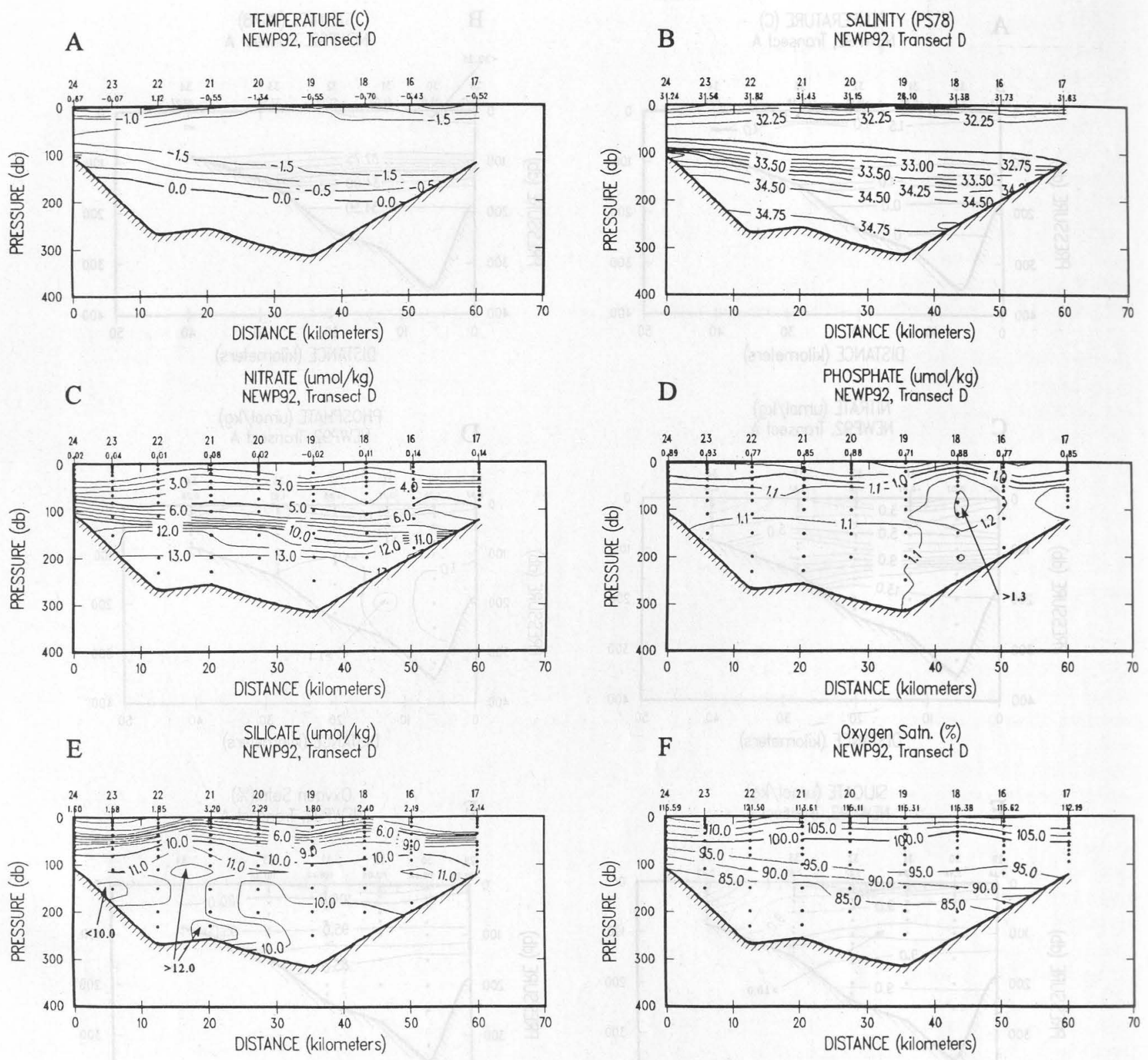

Figure 5. Section plots of (a) potential temperature, (b) salinity, (c) nitrate, (d) phosphate, (e) silicate, and (f) oxygen saturation from transect $D$ in the northeastern polynya.

ties to be viewed in the context of the regional ice cover and geography and can be directly compared with the satellite thermal image in Plate 1.

Nitrate inventories are high and oxygen inventories low at stations in the Southern Trough region, although there are several stations showing patches of depleted nitrate. The latter may be associated with patches of open water toward the end of the summer season.

Within the Northern Trough the heat inventory distribution, despite its much lower spatial resolution (Plate 2a) is consistent with the sea surface temperature (SST) distribution (Plate 1). There is a pool of cold water in the southwestern polynya (transect A; see Figure 1 for locations of transects), apparently emerging from underneath the landfast ice. This water contains high nutrient and low oxygen inventories (Plates $2 b$ and $2 c$ ). Farther to the northeast (in the vicinity of transects B and C), cold water is found squeezed between two areas of warmer water to the north and south, carrying with it high nutrient and low oxygen inventories. According to the satellite imagery, this cold ribbon continues to spread farther to the northeast, and it is very clear in the center of transect $D$. The easternmost transect (E) sampled the EGC, and it can be seen that heat and oxygen inventories are low and nutrient inventories are high within this jet flowing out of the ice-covered Arctic Ocean, except possibly at its southern end (see below).

It therefore appears based on a combination of satellite and hydrographic data that there is a source of cold, high nitrate water emerging from underneath the landfast ice in the southwestern polynya and that this high-nutrient core extends, in a convoluted ribbon, along the axis of the Northern Trough until polynya waters merge with the EGC. 

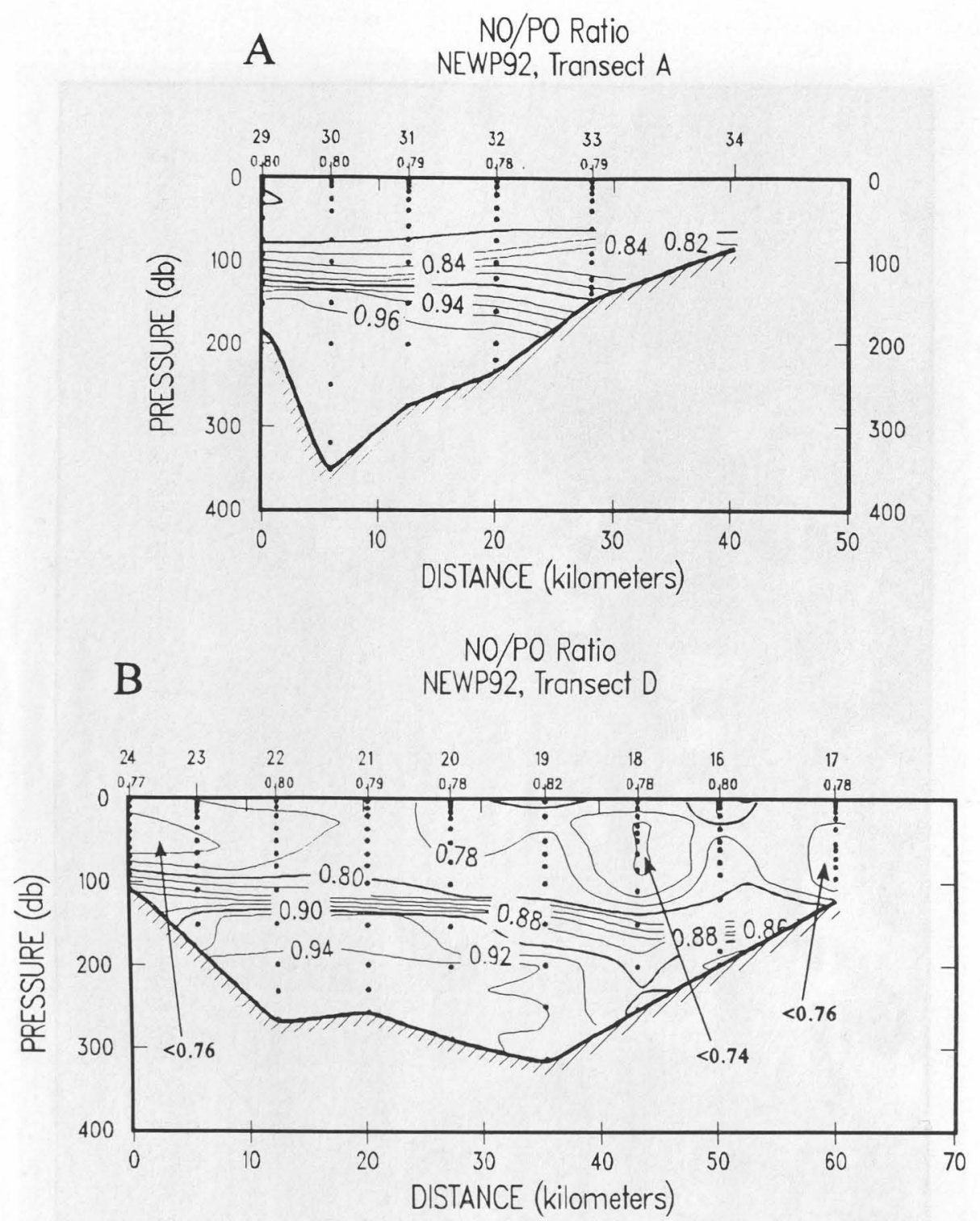

Figure 6. Section plot of the NO/PO ratio (see section 3.3 in the text for details) from (a) transect A in the southwestern polynya and (b) transect $\mathrm{D}$ in the northeastern polynya.

The lower nitrate and higher heat inventories at the southern and northern ends of the transects within the polynya (i.e., at the edges of the cold plume) are suggestive of longer residence times within the ice-free, illuminated, productive polynya.

On the basis of the low nutrient and high oxygen inventories found in the vicinity of the southern end of the easternmost transect (E) the outflowing polynya waters appear to swing to the south at the shelf break and merge with the southward flowing EGC. This merging potentially controls the export of the organic matter produced in the polynya, however, the ultimate fate of the organic matter produced within the polynya (e.g., recirculation over Belgica Bank or southward advection with the EGC with possible shelf export) remains unclear.

\subsection{Along-Trough Distributions: New Production and Elemental Ratios}

Analysis of regional circulation by Bourke et al. [1987] suggested an anticyclonic gyre centered over Belgica Bank, with streamlines within the trough system oriented along the topography (i.e., to the northeast in the Northern Trough). The property distributions discussed in the previous section support this, although they indicate a considerably more complex flow structure involving narrow ribbons of cold water and possible "backwater" or recirculation regions containing warmer water. We have therefore examined the along-trough nutrient and oxygen distributions in order to examine the evidence for progressive nutrient depletion and oxygen evolution within the polynya and, by inference, the rate of net organic carbon production.

"Trough axis" stations north of $79.5^{\circ} \mathrm{N}$ were selected for the examination of lateral gradients, where the sounding depth was $\geq 250 \mathrm{~m}$. Along-trough distance was calculated as the distance from station 42 which is situated in the southwestern polynya (Figure 1). The distributions of nutrients and oxygen inventories versus along-trough distance are presented in Figure $7 \mathrm{a}-7 \mathrm{~d}$, together with regression lines for nutrients and oxygen versus distance. The regression lines are based on data collected west of 


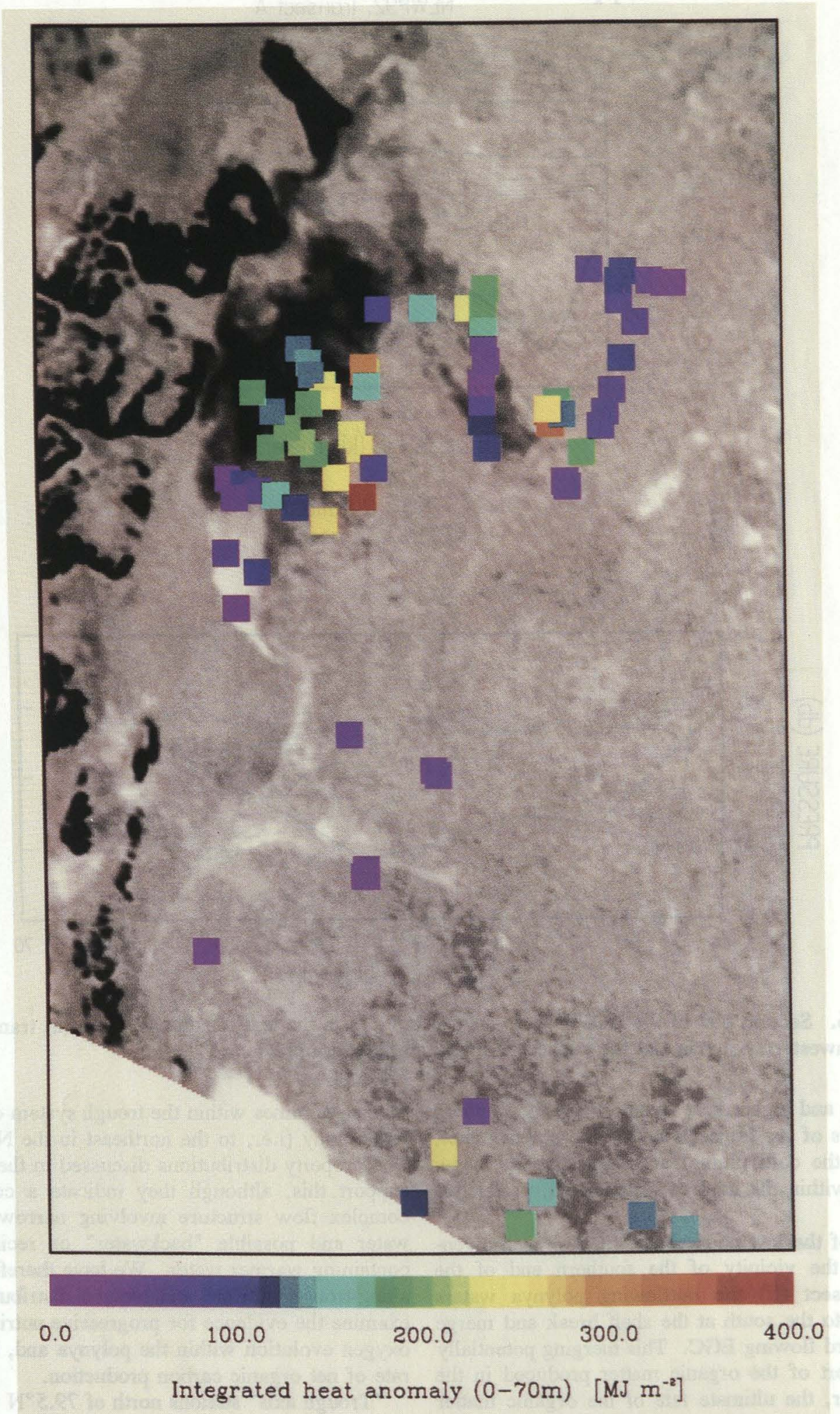

Plate 2. Inventories of (a) heat (megajoules per square meter), (b) nitrate (millimoles per square meter), and (c) dissolved oxygen (moles per square meter) integrated from the surface to $70 \mathrm{~m}$ shown at the station positions superimposed on an AVHRR thermal image of July 23, 1992. See text for details of inventory calculations. The colors representing the concentrations are explained below each image, and the cold water plume emerging from the fast ice is revealed by the light gray in the satellite photo. Note that the station data were derived over several weeks, during which time some details of the ice cover will have changed from those revealed in the satellite image. The main features of the polynya, however, were largely as depicted here for the duration of the cruise. 


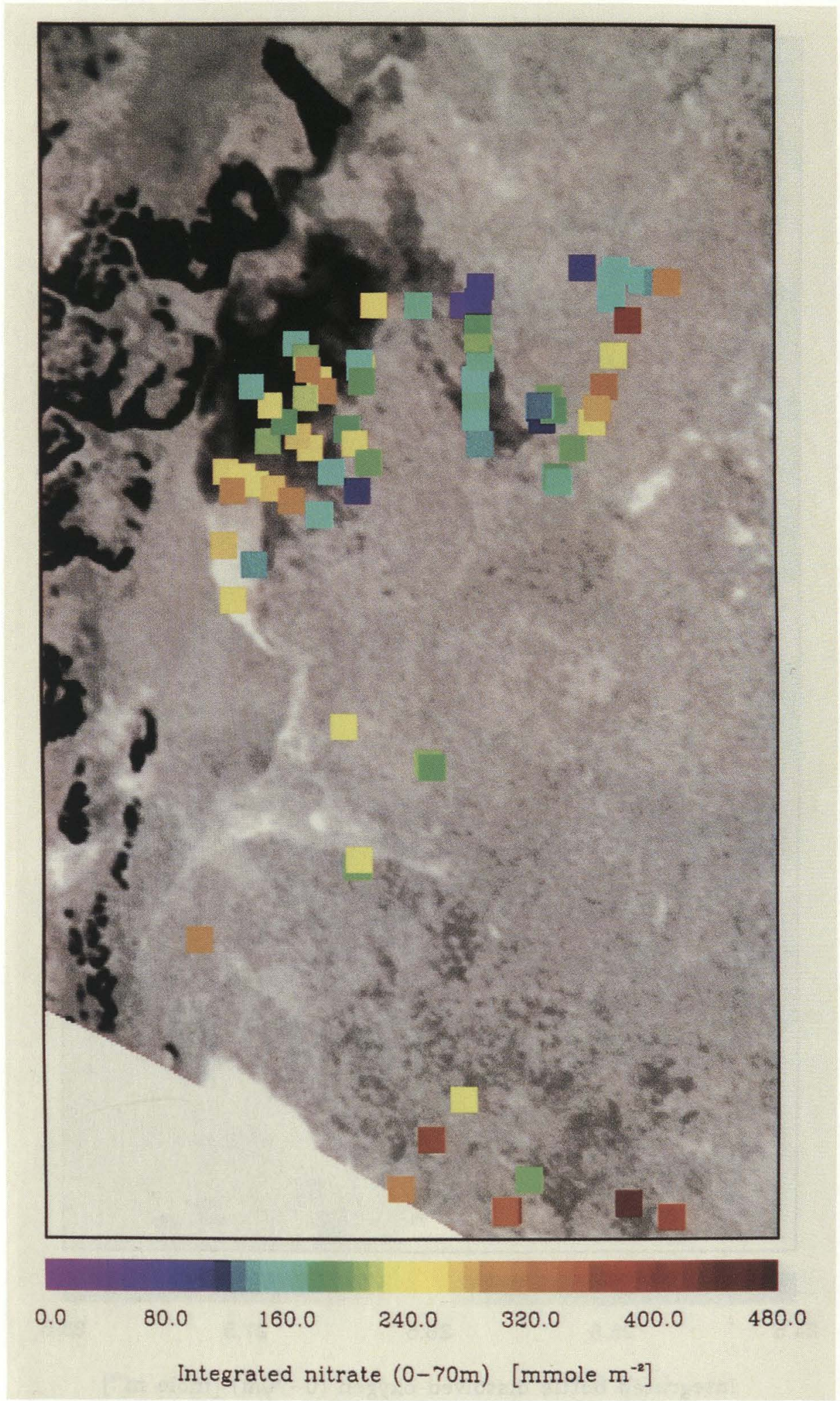

Plate 2. (continued)

$10^{\circ} \mathrm{W}$ to avoid incorporating the stations which sampled within the EGC.

The regression coefficients and their standard errors are presented in Table 1. Statistically significant decreases with along-trough distance were found for nitrate and silicate, and oxygen was found to increase significantly with distance. The phosphate gradient, although it also suggested a decrease with distance, was not statistically significant.
Much of the scatter around the regression lines is due to the cross-trough variability seen in Plate 2 , together with the fact that simply selecting stations in the deepest parts of the trough cannot hope to capture the complex flow pattern which is evident in the satellite imagery.

The distributions confirm a decline in nutrient levels and an increase in oxygen with distance along the trough, from a presumed source under the landfast ice in the southwestern 


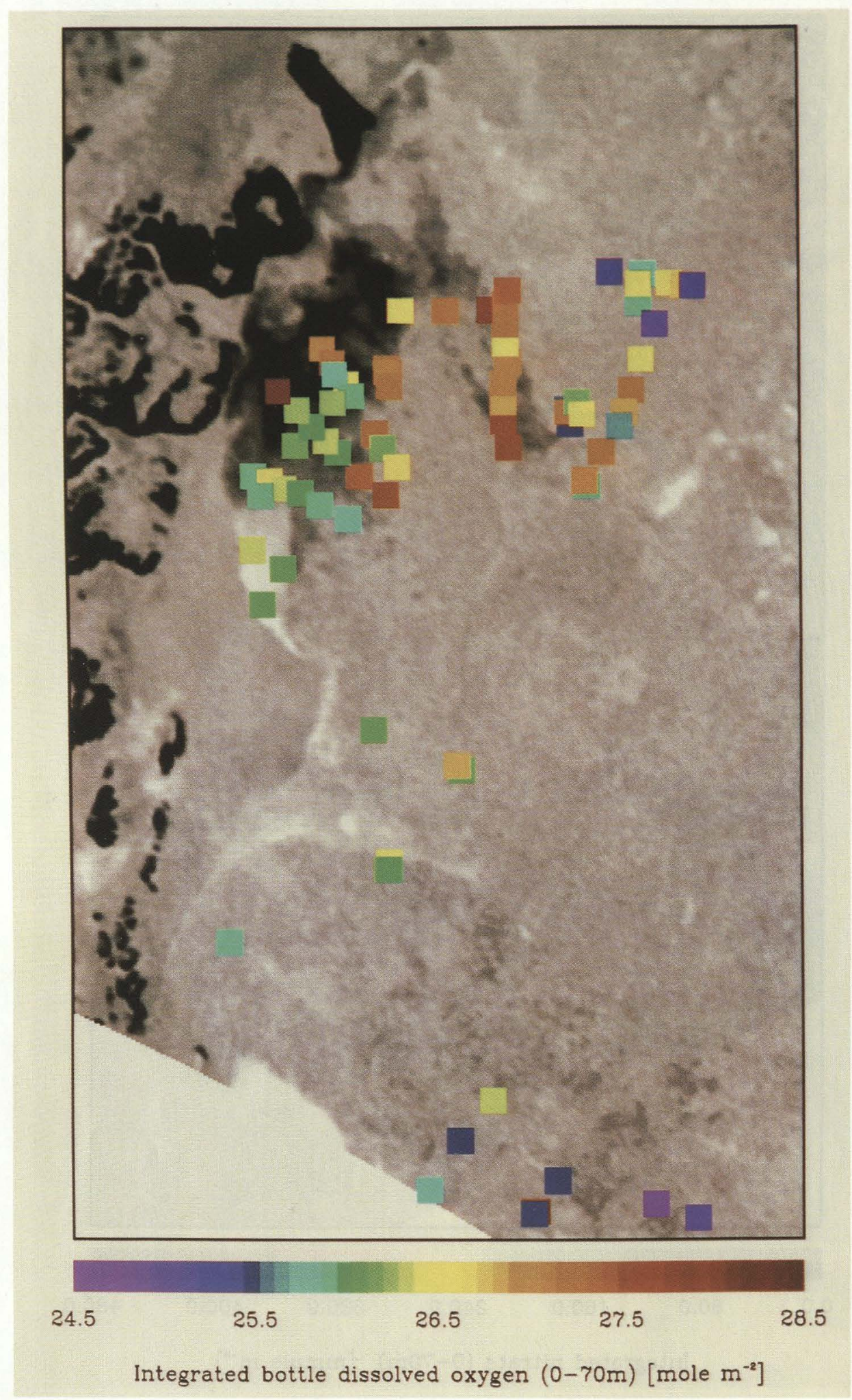

Plate 2. (continued)

polynya (nutrient and oxygen inventories to the south and east of the fast ice are comparable to levels found in the southwestern polynya; Plates $2 b$ and $2 c$ ). Several lines of evidence confirm that this pattern is due to biological production and is not simply due to lateral mixing of water masses. (1) Inventories found within the EGC (which is the logical offshore end-member and was sampled at the easternmost transect, E) lie well above the extrapolated nutrient distance regression lines (Figure 7). (2) Similar regression analyses conducted for $\mathrm{PW}$ samples collected below the euphotic zone (i.e., integrated between 70 and 100 m) showed no significant along-trough trend for nitrate or oxygen (Figures $7 \mathrm{a}$ and $7 \mathrm{~d}$ ).

Correlations between the inventories of nutrients, oxygen and inorganic carbon from stations within the Northern Trough region (i.e., $>79.5^{\circ} \mathrm{N},<10^{\circ} \mathrm{W}$ ) are also consistent 

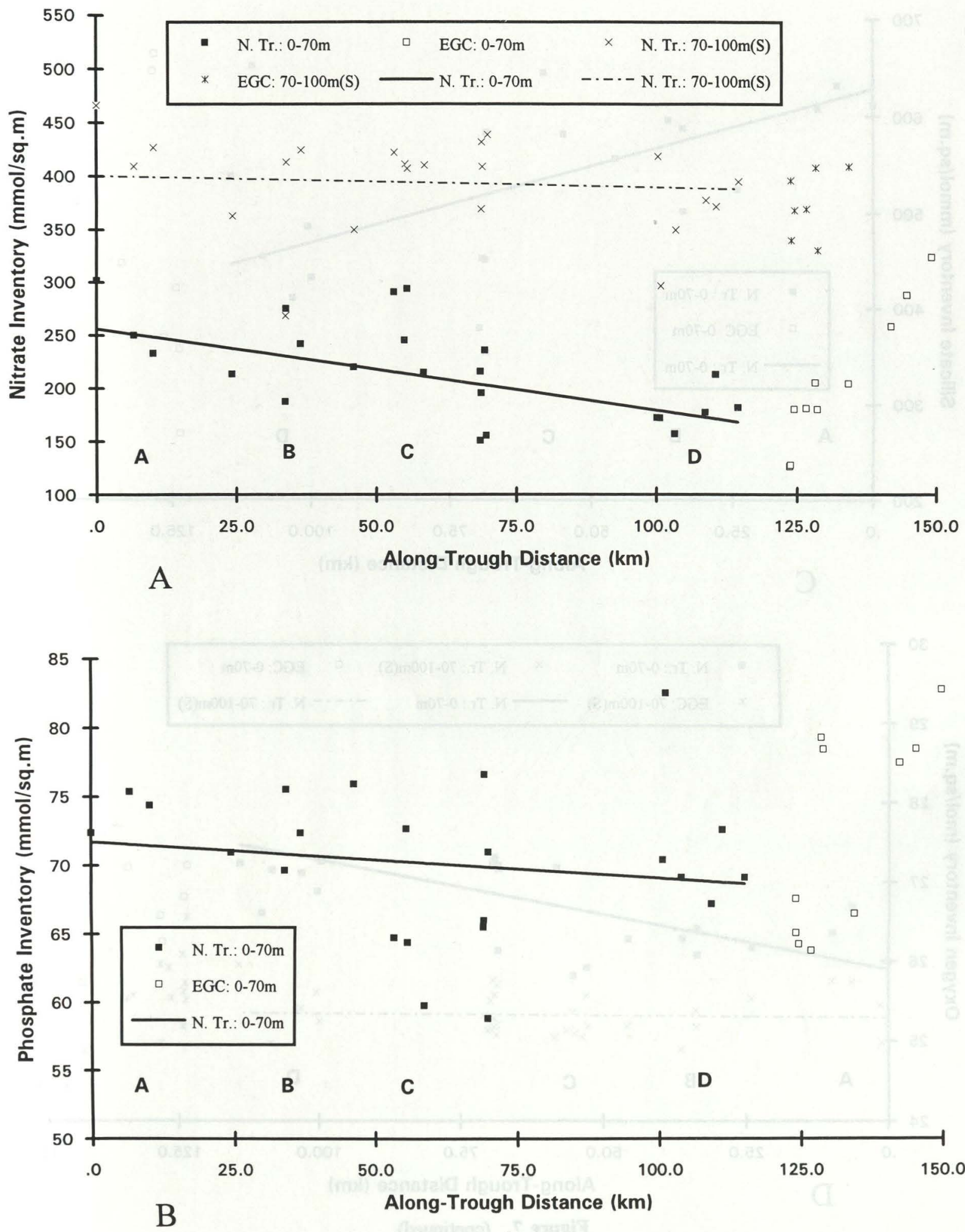

Figure 7. Linear regressions of (a) nitrate, (b) phosphate, (c) silicate, and (d) oxygen inventories (0-70 m) versus the along-trough distance within the polynya. Data are from stations north of $79.5^{\circ} \mathrm{N}$ with sounding depths of $\geq 250 \mathrm{~m}$. Solid symbols represent data from the polynya region; open symbols represent data taken to the east of $10^{\circ} \mathrm{W}$ which are strongly influenced by the East Greenland Current. The nitrate and oxygen plots also includes a separate analysis of inventories between 70 and $100 \mathrm{~m}$. (S) in the legend of $7 \mathrm{a}$ and $7 \mathrm{~d}$ indicates that the inventories between 70 and $100 \mathrm{~m}$ have been scaled by $70 / 30$ in order to allow direct comparison with the inventories in the overlying waters. The locations of transects A, B, C, and D (see Figure 1) are marked. N. Tr. is Northern Trough; EGC is East Greenland Current. 

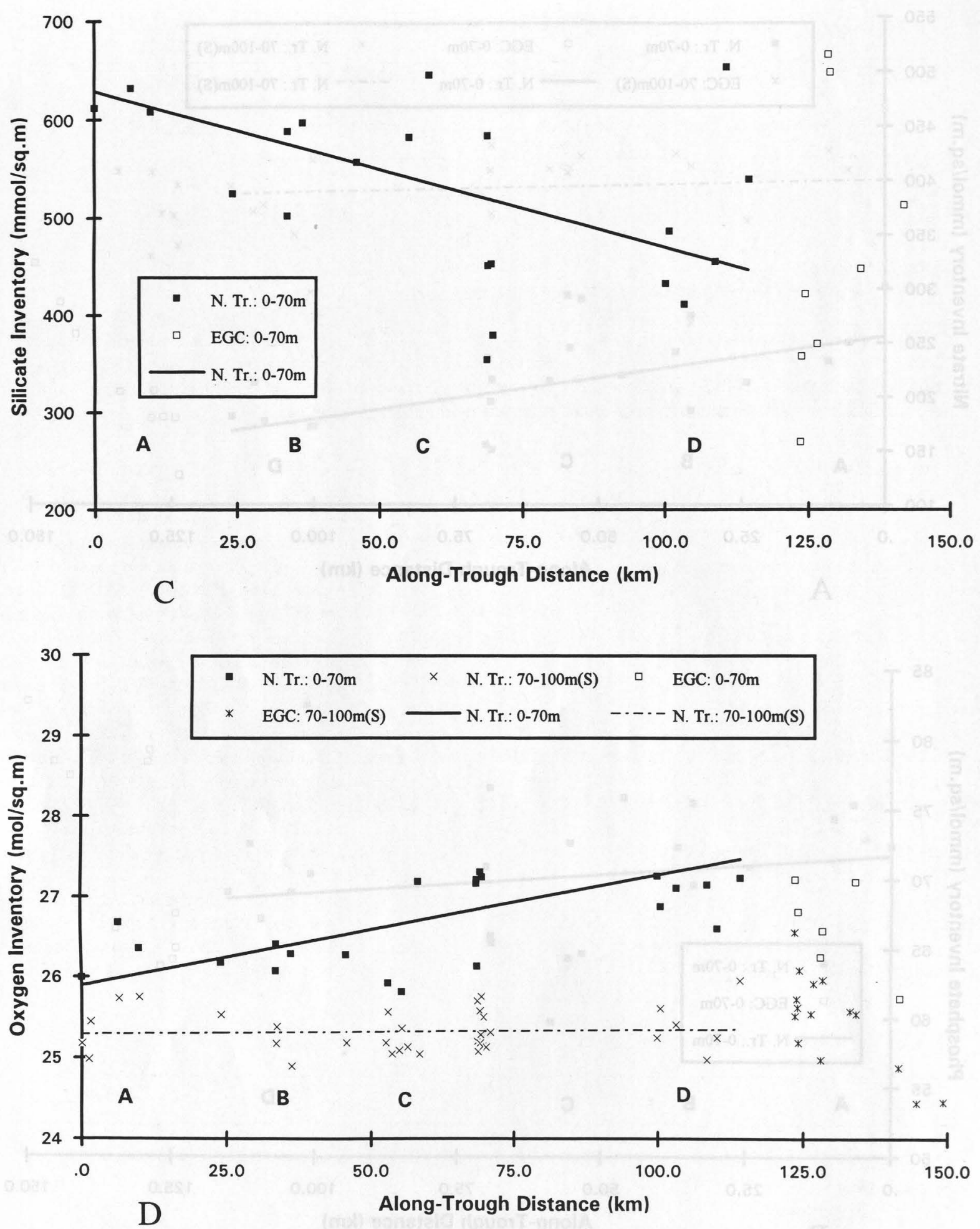

Figure 7. (continued)

with biological production. Dissolved inorganic carbon deficits due to the formation of organic carbon $\left(\mathrm{TCO}_{2}{ }^{*}\right.$ or "B"; see Yager et al. [this issue]), which incorporate corrections for the effects of alkalinity changes and dilution by fresh water, have been calculated for a limited number of stations where samples for inorganic carbon were collected. The regression of $\mathrm{TCO}_{2}{ }^{\circ}$ on $\mathrm{O}_{2}$ inventory gives a slope of -
$0.760( \pm 0.089)$, implying a photosynthetic quotient $\left(\mathrm{O}_{2} / \mathrm{TCO}_{2}\right)$ of $\sim 1.32$, close to the photosynthetic quotient of 1.4-1.5 which is expected on theoretical grounds for new or net community production [Laws, 1991]. It is worth noting, however, that regression of $\mathrm{O}_{2}$ inventory against $\mathrm{TCO}_{2}$ " gave a lower slope for the apparent photosynthetic quotient, $1.23( \pm 0.14)$. The difference illustrates a limita- 
Table 1: Regressions of Along-Trough Nutrient and Oxygen Inventories

\begin{tabular}{lcrrlrr}
\hline Parameter & $\begin{array}{l}\text { Along-Trough } \\
\text { Gradient } \\
\text { mmol m } \mathbf{~ k m}^{-1}\end{array}$ & Intercept & $r^{2}$ & $\begin{array}{l}\text { Gradient } \\
\text { Standard Error } \\
\text { mmol m } \mathbf{~ k m}^{-1}\end{array}$ & $\begin{array}{l}\text { Intercept } \\
\text { Standard Error } \\
\text { mmol m }\end{array}$ & $n$ \\
\hline $\mathrm{NO}_{3}$ & -0.765 & 256.0 & 0.337 & 0.234 & 16.2 & 23 \\
$\mathrm{PO}_{4}$ & 0.276 & 71.7 & 0.027 & 0.035 & 2.4 & 23 \\
$\mathrm{SiO}_{4}$ & -1.591 & 628.8 & 0.193 & 0.709 & 49.1 & 23 \\
$\mathrm{O}_{2}$ & 9.140 & 26096.4 & 0.375 & 2.635 & 184.1 & 22 \\
$\mathrm{NO}_{3}(70-100 \mathrm{~m})$ & -0.108 & 400.5 & 0.006 & 0.306 & 21.2 & 23 \\
$\mathrm{O}_{2}(70-100 \mathrm{~m})$ & 0.498 & 25292.0 & 0.004 & 1.470 & 97.0 & 34
\end{tabular}

The regressions used all stations north of $79.5^{\circ} \mathrm{N}$ and west of $10^{\circ} \mathrm{W}$ for which the total water depth was $>250 \mathrm{~m}$ and for which at least five sample analyses were made in the upper $70 \mathrm{~m}$. The oxygen regressions from $70-100 \mathrm{~m}$ are based on conductivity-temperature-depth (CTD) oxygen sensor data. Abbreviations are $r^{2}$, correlation coefficient squared; $n$, number of samples.

tion of simple linear regression, which assumes variability or measurement error is confined to the $Y$ variable in the regression of $Y$ on $X$. The regression of $\mathrm{TCO}_{2}{ }^{*}$ on $\mathrm{O}_{2}$ inventory is appropriate for the purpose of prediction of the $\mathrm{TCO}_{2}{ }^{*}$ on the basis of an observed oxygen inventory, as is required for the estimation of carbon production from oxygen data (see below). On the other hand, the functional relationship between two inventories, which is better suited for comparisons with photosynthetic quotients, Redfield ratios, or the measured stoichiometric ratios of particulate organic matter, is better estimated using the "geometric mean regression" [see Ricker, 1973]. In this case the functional slope is given by the geometric mean of the slope of the regression of $Y$ on $X$ and the inverse of the slope of the regression of $X$ on $Y$. The geometric mean slope for $\mathrm{O}_{2}: \mathrm{TCO}_{2}{ }^{*}$ is $1.27( \pm 0.14)$. Results of the geometric mean regressions are presented in Tables $2 a$ and $2 b$, together with the predictive regressions of $\mathrm{TCO}_{2}{ }^{*}$ on $\mathrm{O}_{2}$ and $\mathrm{NO}_{3}$ inventories.

The observed $\mathrm{TCO}_{2}{ }^{*}: \mathrm{NO}_{3}$ geometric mean slope of 7.13 $( \pm 1.53)$ is indistinguishable from the expected ratio for marine organic matter [Redfield et al., 1963; Takahashi et al., 1985], as well as from the mean C:N ratio of the particulate organic matter in the study region of $\sim 8$ [Smith et al., this issue). The polynya therefore does not exhibit the elevated C:N consumption ratios reported by Sambrotto et al. [1993], but consumption ratios are consistent with the high-latitude time series studies discussed by Takahashi et al. [1993]. Although the $\mathrm{PO}_{4}: \mathrm{NO}_{3}$ slope is higher than expected from Redfield stoichiometry, it should be noted that this inventory correlation was poor.

The observed $\mathrm{TCO}_{2}{ }^{*}:\left(-\mathrm{O}_{2}\right)$ and $\mathrm{TCO}_{2}{ }^{*}: \mathrm{NO}_{3}$ predictive regressions in Tables $2 a$ and $2 b$ can be combined with the along-trough $\mathrm{NO}_{3}$ and $\mathrm{O}_{2}$ inventory gradients given in Table 1 and an estimated along-trough velocity of $10 \mathrm{~cm} \mathrm{~s}^{-1}(8.64$ $\mathrm{km} \mathrm{d}^{-1}$ ), to estimate the net rate of organic carbon formation for the Northern Trough region. Net production rates of $41.4( \pm 16.1) \mathrm{mmol}(\mathrm{C}) \mathrm{m}^{-2} \mathrm{~d}^{-1}$ are inferred based on the nitrate gradient, with the oxygen gradient implying 60.0 $( \pm 18.7) \mathrm{mmol}(C) \mathrm{m}^{-2} \mathrm{day}^{-1}$.

Given that oxygen was supersaturated throughout the surface waters of the Northern Trough region, it is important to consider to what extent oxygen inventories may have been depleted by air-sea gas exchange. The wind

Table 2a. Observed Regression Slopes Versus Nitrate Inventory

\begin{tabular}{lcccc}
\hline & $\mathrm{TCO}_{2}^{*}$ & $\left(-\mathrm{O}_{2}\right)$ & Silicate & Phosphate \\
\hline $\begin{array}{l}\text { Functional slope } \\
\quad \text { (predictive) }\end{array}$ & 7.134 & 10.554 & 2.231 & 0.089 \\
Standard Error (slope) & $(6.265)$ & & & \\
$r^{2}$ & 1.526 & 1.036 & 0.197 & 0.013 \\
$n$ & 0.77 & 0.61 & 0.67 & 0.14 \\
Takahashi et al. $[1985]$ & 7 & 42 & 45 & 45 \\
Redfield et al. $[1963]$ & $6.50-8.75$ & 10.75 & - & 0.062 \\
& 6.625 & 8.625 & - & 0.062
\end{tabular}

See text for discussion of functional regressions between nutrient, oxygen, and dissolved inorganic carbon inventories. The numbers in parentheses represent the predictive regressions of $\mathrm{TCO}_{2}{ }^{*}$ on $\mathrm{NO}_{3}$ or $\left(-\mathrm{O}_{2}\right)$. The regressions used data from all stations north of $79.5^{\circ} \mathrm{N}$ and west of $10^{\circ} \mathrm{W}$ for which the total water depth was $>70 \mathrm{~m}$ and for which at least five sample analyses were made in the upper $70 \mathrm{~m}$. All inventories, including oxygen, were based on bottle data. $\mathrm{TCO}_{2}{ }^{*}$ represents $\mathrm{TCO}_{2}$ inventories that have been corrected for the effects of alkalinity changes and dilution with freshwater as described by Yager et $a l$. [this issue]; $r^{2}$ is the correlation coefficient squared; and $n$ is the number of samples. 
Table 2b. Observed Regression Slopes Versus $\left(-\mathrm{O}_{2}\right)$ Inventory

\begin{tabular}{lllll}
\hline & $\mathrm{TCO}_{2}{ }^{*}$ & Silicate & Phosphate & Nitrate \\
\hline $\begin{array}{l}\text { Functional slope } \\
\quad \text { (predictive) }\end{array}$ & 0.7855 & 0.210 & 0.0085 & 0.0948 \\
Standard Error (slope) & $(0.7596)$ & & & \\
$r^{2}$ & 0.089 & 0.021 & 0.0012 & 0.0093 \\
$n$ & 0.94 & 0.62 & 0.26 & 0.61 \\
Takahashi et al. $[1985]$ & 7 & 42 & 42 & 41 \\
Redfield et al. $[1963]$ & $0.605-0.814$ & - & 0.0058 & 0.093 \\
& 0.768 & - & 0.0072 & 0.1159 \\
\hline
\end{tabular}

See Table $2 \mathrm{a}$ notes.

speed was low throughout the cruise, $\sim 3.6( \pm 1.4) \mathrm{m} \mathrm{s}^{-1}$ at $10 \mathrm{~m}$ [P. Minnett, unpublished data, 1994]. For an average surface temperature of $2^{\circ} \mathrm{C}$ the Schmidt number formulation of Wanninkhof [1992] and the gas transfer formulations of Wanninkhof [1992] and Liss and Merlivat [1986] give gas transfer velocities for oxygen of 2.49 and $0.38 \mathrm{~cm} \mathrm{~h}^{-1}$, respectively. It should be noted that the proximity of ice cover and land restricted the effective fetch within the region, which may imply lower gas transfer velocities for a given wind speed (see discussion by Wanninkhof [1992]). For a mean surface oxygen saturation of $115 \%$ these transfer velocities imply that $3-18 \%$ of the observed oxygen inventory increase would be lost to the atmosphere during a mean residence time of surface water along the trough axis of $\sim 6$ days. Yager et al. [this issue] show that the effect of gas exchange for $\mathrm{CO}_{2}$ inventories was negligible during the period of the cruise. Hence the observed along-trough increase of oxygen underestimates the biological production of oxygen by this amount, which may be reflected in the apparent photosynthetic quotient $\left(\mathrm{O}_{2} / \mathrm{TCO}_{2}\right)$ being $\sim 12 \%$ lower than the theoretical value (see above). The latter implies that use of an apparent, empirical photosynthetic quotient based on our limited set of in situ observations, rather than a theoretical value, helps compensate for the influence of gas exchange on the oxygen-based production estimate.

The production estimates are in good agreement with independent estimates of $35.8 \mathrm{mmol}(\mathrm{C}) \mathrm{m}^{-2} \mathrm{~d}^{-1}$ based on observed along-trough gradients in light transmission [Smith et al., this issue] and 15-53 mmol(C) $\mathrm{m}^{-2} \mathrm{~d}^{-1}$ based on ${ }^{234} \mathrm{Th}$ fluxes [Cochran et al., this issue]. These production estimates represents the formation rate of organic carbon which is available for export from the euphotic zone. Note that the carbon is not necessarily exported: for example it may be subsequently regenerated in situ. Yager et al. [this issue] discuss the issue of export in more detail. The observation of substantial silicate removal suggests that the production was mediated largely by diatoms, which is borne out by phytoplankton species observations [Smith et al., this issue].

It is anticipated that when hydrographic and current meter [M. Johnson, unpublished data, 1994] data are fully analyzed, a more accurate estimate for the along-trough velocity will be obtained. It will then be possible to rescale the production estimate to a more appropriate velocity. In the meantime it is important to note that the water meanders considerably as it flows to the northeast. Hence the true along-trough flow path may be considerably longer than the linear distance assumed above. In addition, there may be significant cross-axis diffusion of nutrients into the lownutrient regions to the north and south of the along-axis flow. Both factors imply that our estimates are quite likely to overestimate the net organic carbon production rate.

\subsection{Inventory Correlations With Heat}

The distributions of nutrients and oxygen suggest that their inventories vary with the residence time of PW within the polynya. However, in order to estimate rates, we performed a "core layer" analysis using only the central trough stations and an assumed current velocity. Given that there was a net input of heat to the water column in ice-free regions [Minnett, this issue], we initially hypothesized that there might be a more general, polynya-wide relationship between the nutrient/oxygen inventories and the integrated heat anomaly within the PW. If that were the case, then it would be possible to estimate the net organic matter production rate using all of the available stations and based on a knowledge of the heat budget of the polynya, rather than depending on a spatially and temporally variable current velocity.

However, although good correlations with heat were found at stations confined to the axis of the central trough (see also Smith et al. [this issue], who examined correlations of suspended particulate matter with temperature at these stations), these correlations broke down elsewhere, so that it was not possible to define a statistically significant relationship for the polynya as a whole. The most likely reasons for the poor overall correlation include temporal variability in the surface heat flux, particularly the role of variable ice cover in removing heat from a previously illuminated (hence nutrient depleted) water column.

\section{Conclusions}

The Northeast Water Polynya is shown to have low N:P ratios in the polar water mass, indicative of an ultimate source in the Pacific sector of the Arctic Ocean. This low $\mathrm{N}: \mathrm{P}$ ratio originating on Arctic shelves is hypothesized to cause nitrate to be the limiting nutrient along the eastern seaboard of North America as far south as Cape Hatteras. The polynya is shown to be strongly influenced by a plume of cold, relatively nutrient-rich water emerging from underneath landfast ice. This plume creates a quasi-steady, spatially expressed progression from nutrient replete to nutrient limited conditions within the polynya, which is 
expressed both along and across the principal axis of flow. The nutrient and oxygen gradients are shown to be caused by biological processes, rather than by water mass mixing. Although there is considerable small-scale variability which introduces noise into the relationship, the observed depletion of nitrate and increase of oxygen implies a net organic carbon formation rate of $40-60 \mathrm{mmol}(\mathrm{C}) \mathrm{m}^{-2} \mathrm{~d}^{-1}$. The distributions of nutrient, oxygen, and inorganic carbon inventories [Yager et al., this issue] are also consistent with the stoichiometry of marine organic matter proposed by Redfield et al. [1963] and Takahashi et al. [1985], given relatively large uncertainties.

The easternmost transects of our study suggest that nutrient-depleted, oxygen-rich water merges with the southward flowing EGC at the shelf break. This also represents a potential pathway for the export of organic carbon, however, consideration of the ultimate fate of such carbon (e.g., export with the EGC or recirculation onto the shelf) requires further study.

Acknowledgements. The authors would like to acknowledge the extensive cooperation of the U.S. Coast Guard, particularly Captain C. Gary Boyer and the officers and crew of the USCGC Polar Sea. The chemistry program would not have been possible without sampling assistance by Shelly Carpenter, Ann Close, and Lee-Ann Clotfelder and CTD operations by Bill Behrens, John Smithheisler, and Dave Vogel. Nutrient and oxygen measurements were made by Craig Neill, Dennis Guffey, and Bob Ramirez. Mark Johnson provided bathymetry data. Stefan Einarsson and Svend Malmberg of the Marine Research Institute, Reykjavik, generously provided last minute technical assistance. Discussions with Carin Ashjian, Kirk Cochran, and Patricia Yager contributed significantly to the ideas in this manuscript. This work was supported by the National Science Foundation Office of Polar Programs through a grant to J.K. Cochran (State University of New York).

\section{References}

Anderson, L., and D. Dyrssen, Chemical constituents of the Arctic Ocean in the Svalbard area, Oceanol. Acta, 4, 305311, 1981.

Benson, B.B., and D. Krause, The concentration and isotopic fractionation of oxygen dissolved in freshwater and seawater in equilibrium with the atmosphere, Limnol. Oceanogr., 29(3), 620-632, 1984.

Bourke, R.H., J.L. Newton, R.G. Paquette, and M.D. Tunnicliffe, Circulation and water masses of the East Greenland shelf, J. Geophys. Res., 92(C7), 6729-6740, 1987.

Broecker, W.S., "NO", a conservative water-mass tracer, Earth Planet. Sci. Lett., 23, 100-107, 1974.

Carpenter, J.H., The Chesapeake Bay Institute technique for the Winkler dissolved oxygen method, Limnol. Oceanogr., 10, 141-143, 1965.

Chapman, D.C., and R.C. Beardsley, On the origin of shelf water in the Middle Atlantic Bight, J. Phys. Oceanogr., 19, 384-391, 1989.

Chen, C-T.A., Preliminary observations of oxygen and carbon dioxide of the wintertime Bering Sea marginal ice zone, Cont. Shelf Res., 4(4), 465-484, 1985.

Cochran, J.K., C. Barnes, D. Achman, and D. Hirschberg, The ${ }^{234} \mathrm{Th} /{ }^{238} \mathrm{U}$ disequilibrium as an indicator of scavenging rates and carbon fluxes in the Northeast Water Polynya, Greenland, J. Geophys. Res., this issue.

Codispoti, L.A., G.E. Friederich, C.M. Sakamoto, and L.I. Gordon, Nutrient cycling and primary production in the marine systems of the Arctic and Antarctic, J. Mar. Syst., 2, 359-384, 1991.

Culberson, C.H., Dissolved oxygen, in WOCE Operations Manual, Volume 3: The Observational Programme, part 3.1.3.: WHP Operations and Methods, World Hydrographic Progamme Office Rep. WHPO 91-1, WOCE Rep. 68/91, Woods Hole Oceanogr. Inst., Woods Hole, Mass., July 1991.

Gordon, L.I., J.C. Jennings, A.A. Ross, and J.M. Krest, A suggested protocol for continuous flow automated analysis of seawater nutrients, in WOCE Operations Manual, Volume 3: The Observational Programme, part 3.1.3: WHP Operations and Methods, World Hydrographic Program Office Rep. WHPO 91-1, WOCE Rep. 68/91, Woods Hole Oceanogr. Inst., Woods Hole, Mass., July 1991.

Jones, E.P., and L.G. Anderson, On the origin of the chemical properties of the Arctic Ocean halocline, J. Geophys. Res., 91(C9), 10,759-10,767, 1986.

Ketchum, B.H., R.F. Vaccaro, and N. Corwin, The annual cycle of phosphorus and nitrogen in New England coastal waters, J. Mar. Res., 17, 282-301, 1958.

Laws, E.A., Photosynthetic quotients, new production and net community production in the open ocean, Deep Sea Res., Part A 38(1), 143-167, 1991.

Liss, P.S., and L. Merlivat, Air-sea gas exchange rates: Introduction and synthesis, in The Role of Air-Sea Exchange in Geochemical Cycling, edited by P. Buat-Menard, pp.113129, D. Reidel, Norwell, Mass., 1986.

Minnett, P.J., Measurements of the summer surface heat budget of the Northeast Water Polynya in 1992, J. Geophys. Res., this issue.

Moore, R.M., M.G. Lowings, and F.C. Tan, Geochemical profiles in the central Arctic Ocean: Their relation to freezing and shallow circulation, J. Geophys. Res., 88(C4), 2667-2674, 1983.

NEWATER Steering Committee and Principal Investigators, Northeast Water Polynya: Polar Sea cruise results, Eos Trans AGU, 74(16), 185, 195-196, 1993.

Owens, W.B., and R.C. Millard Jr., A new algorithm for CTD oxygen calibration, J. Phys. Oceanogr., 15(5), 621-631, 1985.

Redfield, A.C., B.H. Ketchum, and F.A. Richards, The influence of organisms on the composition of seawater, in The Sea, vol. 2, edited by M.N. Hill, pp. 26-77, John Wiley, New York, 1963.

Ricker, W.E., Linear regression in fishery research, J. Fish. Res. Board. Can., 30, 409-434, 1973.

Ryther, J.H., and W.M. Dunstan, Nitrogen, phosphorus and eutrophication in the coastal marine environment, Science, 171, 1008-1013, 1971.

Sambrotto, R.N., G. Savidge, C. Robinson, P. Boyd, T. Takahashi, D.M. Karl, C. Langdon, D. Chipman, J. Marra, and $\mathrm{L}$. Codispoti, Elevated consumption of carbon relative to nitrogen in the surface ocean, Nature, 363, 248-250, 1993.

Smith, W.O., Jr., Primary productivity and new production in the Northeast Water (Greenland) Polynya during summer, 1992, J. Geophys. Res., this issue.

Smith, W.O.. Jr., I.D. Walsh, B.C. Booth, and J.W. Deming, Particulate matter and phytoplankton and bacterial biomass distributions in the Northeast Water Polynya during summer 1992, J. Geophys. Res., this issue.

Struzik, E., Arctic oases, Equinox, 48, 38-49, 1989.

Takahashi, T., W.S. Broecker, and S. Langer, Redfield ratio 
based on chemical data from isopycnal surfaces, J. Geophys. Res., 90(C4), 6907-6924, 1985.

Takahashi, T., J. Olafsson, J.G. Goddard, D.W. Chipman, and S.C. Sutherland, Seasonal variation of $\mathrm{CO}_{2}$ and nutrients in the high-latitude surface oceans: A comparative study, Global Biogeochem. Cycles, 7(4), 843-878, 1993.

Wallace, D.W.R., T.S. Hopkins, W.J. Behrens, C. Kinder, W.O. Smith, Z. Top and I.D. Walsh, Collaborative research on the Northeast Water polynya: Hydrographic cruise report, USCGC Polar Sea cruise, July 15 - August 15, 1992, Informal Rep., in press, Brookhaven Natl. Lab., Upton, N.Y., 1995.

Wanninkhof, R., Relationship between wind speed and gas exchange over the ocean, J. Geophys. Res., 97(C5), 73737382. 1992.

Whitledge, T., S. Malloy, C. Patton, and C.D. Wirick, Automated nutrient analysis in seawater, Tech. Rep. BNL 51398, Brookhaven Natl. Lab., Upton, N.Y., 1981.

Wilson, C., and D.W.R. Wallace, Using the nutrient ratio $\mathrm{NO} / \mathrm{PO}$ as a tracer of continental shelf waters in the central Arctic Ocean, J. Geophys. Res., 95(C12), 22,193-22,208, 1990.
World Ocean Circulation Experiment (WOCE), WOCE Operations Manual, Volume 3: The Observational Programme, part 3.1.2: Requirements for WHP data reporting, World Hydrographic Office Rep. WHPO 90-1, WOCE Rep. 67/91, Woods Hole Oceanogr. Inst., Woods Hole, Mass., July 1991.

Yager, P.L., D.W.R. Wallace, K.M. Johnson, W.O. Smith Jr., P.J. Minnett, and J.W. Deming, The Northeast Water Polynya as an atmospheric $\mathrm{CO}_{2}$ sink: A seasonal rectification hypothesis, J. Geophys. Res., this issue.

T.S. Hopkins, Department of Marine, Earth and Atmospheric Sciences, North Carolina State University, P.O. Box 8208, Raleigh, NC 27695.

P.J. Minnett and D.W.R. Wallace, Oceanographic and Atmospheric Sciences Division, Department of Applied Science, Brookhaven National Laboratory, P.O. Box 5000, Upton, NY 11973.

(Received January 31, 1994; revised July 26, 1994; accepted August 18, 1994). 